\title{
Comité científico Congreso chileno de Radiología 2018
}

\section{Sebastián Bravo Grau ${ }^{1, *}$}

1. Radiólogo. Pontificia Universidad Católica de Chile. Santiago, Chile. Director Científico Congreso Chileno de Radiología 2018.

El Congreso Chileno de Radiología es el principal evento de difusión científica y educacional de nuestra Sociedad. En los últimos congresos uno de los principales objetivos ha sido de proteger y fortalecer el espacio a la difusión científica.

Para esto se han tomado tres medidas principales: aumentar el número de trabajos aceptados, especialmente en modalidad oral y póster impreso, aumentar los incentivos en premios y disponer de espacio privilegiado dentro de los bloques para las presentaciones orales científicas.

En el recién pasado Congreso Chileno de Radiología 2018 se recibieron 166 resúmenes de trabajos. En la revisión de los trabajos participó un comité evaluador de más de 40 radiólogos de una decena de centros de nuestro país. Fueron aceptados 23 trabajos científicos para presentación oral, número que ha ido en aumento progresivo en los últimos años.

En este mismo sentido, se presentaron 40 trabajos como pósters impresos la mayoría corresponde a revisiones educacionales, y fueron exhibidos en una ubicación central dentro del centro de eventos lo que dio la oportunidad a los asistentes de visitarlos fácilmente y así aumentar el impacto de estos trabajos.

Un total de 77 trabajos fueron aceptados para modalidad digital, presentaciones que van siendo almacenados y quedan disponibles en el portal educacional estas en el sitio web de la Sociedad.

En los últimos años se ha puesto énfasis en el mérito científico para la evaluación de los trabajos originales, en específico en la metodología, diseño del estudio, análisis de resultados y pertinencia de la discusión.

Finalmente, los trabajos científicos y pósters educacionales ganadores son seleccionados para publicación en la Revista Chilena de Radiología, con el objetivo de potenciar nuestra principal herramienta de difusión científica escrita y que más lectores dentro de Chile y Sudamérica tengan acceso a este material.

Es un permanente desafío de toda la comunidad radiológica el motivar tanto a residentes como radiólogos en participar y desarrollar actividad científica, así como de trabajos educacionales, los que tienen y deberán tener siempre un espacio privilegiado de difusión en nuestro Congreso. Queda abierta la invitación a seguir colaborando para que nuestro congreso se mantenga como una instancia de difusión y aprendizaje para nuestra comunidad radiológica. 